\title{
Novel Observations of Peroxiredoxin-2 Profile and Protein Oxidation in Skeletal Muscle From Pigs of Differing Residual Feed Intake and Health Status
}

Brian M. Patterson ${ }^{1}$, Amanda C. Outhouse ${ }^{1}$, Emma T. Helm ${ }^{1}$, Logan Johnson ${ }^{1}$, Edward M. Steadham ${ }^{1}$, Jack C. M. Dekkers ${ }^{1}$, Kent J. Schwartz ${ }^{2}$, Nicholas K. Gabler ${ }^{1}$, Steven M. Lonergan ${ }^{1}$, and Elisabeth Huff-Lonergan ${ }^{1 *}$

${ }^{1}$ Department of Animal Science, lowa State University, Ames, lowa 50011, USA

${ }^{2}$ Department of Veterinary Diagnostic and Production Animal Medicine, lowa State University, Ames, lowa 50011, USA

*Corresponding author. Email: elonerga@iastate.edu (Elisabeth Huff-Lonergan)

\begin{abstract}
This study's objective was to determine the impact of a dual respiratory and enteric bacterial health challenge on the antioxidant protein peroxiredoxin-2 (Prdx-2) profile and protein oxidation in the skeletal muscle of pigs from 2 lines that were divergently selected for residual feed intake (RFI). The hypotheses were that (1) differences exist in the Prdx-2 profile between 2 RFI lines and infection status and (2) muscle from less efficient high-RFI and health-challenged pigs have greater cellular protein oxidation. Barrows $(50 \pm 7 \mathrm{~kg}, N=24)$ from the 11th generation of the high-RFI $(n=12)$ and low-RFI $(n=$ 12) Iowa State University lines were used. Pigs ( $n=6$ per line) were inoculated with Mycoplasma hyopneumoniae and Lawsonia intracellularis (MhLI) on day 0 post infection to induce a respiratory and enteric health challenge. Uninoculated pigs served as controls ( $n=6$ per line). Necropsy was at $21 \mathrm{~d}$ post infection. Sarcoplasmic protein oxidation, various forms of Prdx-2, and glyceraldehyde 3-phosphate dehydrogenase (GAPDH) content were determined. Neither RFI line nor infection status significantly affected protein carbonylation. Under nonreducing conditions, MhLI pigs had a greater amount of a slower-migrating GAPDH band $(P=0.017)$, indicating oxidative modification. Regardless of health status, the low-RFI pigs had less total Prdx-2 $(P=0.035)$, Prdx-2 decamer $(P=0.0007)$, and a higher ratio of hyperoxidized peroxiredoxin relative to Prdx-2 $(P=0.028)$ than the high-RFI pigs. The increased pool of active Prdx-2 in high-RFI pigs suggests greater oxidative stress in muscle in high- versus low-RFI pigs. The increase in oxidized GAPDH seen in muscle from MhLI pigs_-particularly the high-RFI MhLI pigs_-may be a response to the greater oxidative stress in the high-RFI MhLI. This work suggests that antioxidant proteins are important in growth and health-challenge situations.
\end{abstract}

Key words: glyceraldehyde 3-phosphate dehydrogenase, peroxiredoxin-2, pig, protein oxidation, residual feed intake, skeletal muscle

Meat and Muscle Biology 5(1): 23, 1-15 (2021)

doi:10.22175/mmb.12241

Submitted 8 January 2021

Accepted 14 February 2021

\section{Introduction}

Improving the efficiency of pork production is paramount as the global demand for animal protein increases. Two factors that have a significant impact on pork production are feed efficiency and response to disease challenges. Oxidative stress directly impacts both of these factors (Bottje et al., 2002; Deblanc et al., 2013; Grubbs et al., 2013a; Sies et al., 2017). Oxidative stress favors oxidation in the intricate balance of prooxidant and antioxidant forces within the cell (Sies et al., 2017). Uncontrolled oxidation leads to damage to cellular components, including proteins, lipids, and DNA under oxidative stress conditions. The imbalance continues with a cellular response that redirects energy toward repairing oxidative stress instead of energy for growth. More indepth research is needed to improve understanding of the physiological balance between oxidative stress, health-challenge response, and feed efficiency. 
Animals that have been divergently selected for residual feed intake (RFI) represent a valuable model for comparing animals that differ in feed efficiency. As a measure of feed efficiency, RFI is the difference between an animal's observed feed intake and the expected feed intake based on average daily gain and backfat measurements. Low-RFI (LRFI) pigs are more efficient than their high-RFI (HRFI) counterparts (Boddicker et al., 2011). Grubbs et al. (2013a) found that the more efficient LRFI pigs exhibited less electron leakage and reactive oxygen species (ROS) production in the skeletal muscle mitochondria, suggesting a role for oxidative stress in animals of differing efficiency.

Pathogen challenges cause increased oxidative stress in livestock species, most likely due to increased mitochondrial electron leakage and ROS formation (Deblanc et al., 2013; Sies et al., 2017). Mycoplasma hyopneumoniae is a common respiratory pathogen, and Lawsonia intracellularis is a common enteric pathogen. Both are widespread across commercial swine facilities in the United States. Understanding how these disease challenges impact muscle is important in livestock production.

Antioxidant proteins mitigate oxidative stress and protect living tissues by converting ROS to more stable compounds. Peroxiredoxin-2 (Prdx-2) has a role in responding to oxidative stress challenges in tissues by catalyzing the conversion of hydrogen peroxide $\left(\mathrm{H}_{2} \mathrm{O}_{2}\right)$ and other hydroperoxides to more stable molecules such as water (Karplus, 2015). Prdx-2 plays a role in different metabolic pathways, including mediating insulin sensitivity (Fazakerley et al., 2018; Kim et al., 2018). Several oxidative stress challenges in livestock-including heat stress (Cruzen et al., 2015), LPS immune challenge (Outhouse et al., 2015), physiological stress (Marco-Ramell et al., 2016), and health challenge (Genini et al., 2012) - affect abundance and profile of Prdx-2.

Glyceraldehyde 3-phosphate dehydrogenase (GAPDH) is unique because of its intermediate susceptibility to oxidation by $\mathrm{H}_{2} \mathrm{O}_{2}$ (Baty et al., 2005). As a result, GAPDH and its oxidation state may play a role in both metabolic and redox regulation (Hildebrandt et al., 2015; Peralta et al., 2015). There is also evidence that GAPDH oxidation may play a role in immune response (Kornberg et al., 2018).

To our knowledge, no study has compared the various Prdx-2 oxidation states and oligomeric structures in the skeletal muscle of livestock that differ in feed efficiency or under a health challenge. Defining the role of Prdx-2 in muscle metabolism and growth-especially as it relates to growth efficiency-will uncover new pathways to intervene and improve pig response to stress.

This study's objective was to determine the impact of dual infection with M. hyopneumoniae and L. intracellularis (MhLI) on Prdx-2 protein profile and oxidation of sarcoplasmic proteins in the skeletal muscle of pigs from lines that were divergently selected for RFI. The hypotheses were that (1) differences exist in the Prdx-2 profile based on RFI line and infection status and (2) more protein oxidation occurs in longissimus muscle from less efficient HRFI and health-challenged pigs.

\section{Materials and Methods}

\section{Animals, treatment, and experimental design}

The pigs used in this study were a subset of a larger project (Helm et al., 2018a, 2018b). All animals in this study were handled following approval of the Iowa State University Institutional Animal Care and Use Committee (\#6-16-8298-S). Six littermate pair barrows from the LRFI line and 6 littermate pair barrows from the HRFI line from the 11th generation of the Iowa State University RFI Project were randomly selected from a larger set of pigs (24 selected from 100). At $50 \pm 7 \mathrm{~kg}$ body weight, littermate pairs were split and randomly assigned to individual pens in 2 separate rooms in the same barn (health challenged and control), resulting in 6 HRFI and 6 LRFI pigs in each room. The rooms had identical feeders, flooring, heating and cooling systems, water supply, and pen size. All pigs were provided ad libitum access to a commercial corn-soybean diet and to water (Helm et al., 2018a). On $0 \mathrm{~d}$ post infection (dpi), barrows in the health-challenged room were inoculated with $M$. hyopneumoniae and L. intracellularis, whereas those in the control room were inoculated with a sham. For the respiratory inoculation, M. hyopneumoniae was dosed in a $10 \mathrm{~mL}$ inoculum (strain 232, containing $10^{5}$ color-changing units $/ \mathrm{mL}$ ) through an intratracheal gavage. For the enteric challenge, pigs were intragastrically gavaged with $40 \mathrm{~mL}$ of $L$. intracellularis inoculum $(2 \mathrm{~mL}$ gut homogenate, containing $2 \times 10^{7} \mathrm{~L}$. intracellularis organisms). Inoculums were prepared at the Iowa State University Veterinary Diagnostic Laboratory (Ames, Iowa). This resulted in a $2 \times 2$ factorial design with 4 experimental groups, including LRFI control, LRFI infected, HRFI control, and HRFI infected ( $N=24$ total, $n=6$ pigs per group) (Helm et al., 2018b). Criteria for confirmation of challenge included daily observation, sera antibody at 
dpi 21, and lesion scoring at dpi 21. All MhLI pigs were confirmed positive for both pathogens (Helm et al. 2018b). Less robust signs of infection - including daily observations and lung and small intestine lesion scoring at necropsy-indicated that the challenge resulted in subclinical disease (Helm et al., 2018b). On 21 dpi (projected peak infection), pigs were euthanized using a captive bolt stunning device followed by exsanguination. A section of the longissimus lumborum from between the 10th and 12th rib was immediately removed, trimmed to remove adipose and connective tissue, and homogenized in liquid nitrogen. Samples were held at $-80^{\circ} \mathrm{C}$ until protein extraction.

\section{Sarcoplasmic protein extraction and sample preparation}

Sarcoplasmic proteins were extracted according to Cruzen et al. (2015). Powdered longissimus muscle $(1.5 \mathrm{~g})$ was homogenized in $5 \mathrm{~mL}$ of ice-cold $\left(4^{\circ} \mathrm{C}\right)$ extraction buffer composed of $50 \mathrm{mM}$ Tris- $\mathrm{HCl}, 1$ mM EDTA ( $\mathrm{pH}$ 8.5). Samples were homogenized with a Polytron PT 3100 (Lucerne, Switzerland) for approximately $20 \mathrm{~s}$. The homogenate was centrifuged at $40,000 \times g$ for $20 \mathrm{~min}$ at $4^{\circ} \mathrm{C}$ (Sorvall Super T21, Newtown, CT). The supernatant was filtered with cheesecloth to clarify the sarcoplasmic fraction. The protein content of sarcoplasmic fraction was determined (Lowry et al., 1951) using premixed reagents (BioRad, Hercules, CA). Four $\mathrm{mg} / \mathrm{mL}$ reduced and nonreduced ( $\pm \beta$-mercaptoethanol) protein samples for sodium dodecyl sulfate one-dimensional polyacrylamide gel electrophoresis (SDS-PAGE) and western blot analysis were produced by adding 0.5 volumes (relative to the volume of the protein sample) of Wang's tracking dye (3 mM EDTA, 3\% [w:v] SDS, $30 \%$ [v:v] glycerol, $0.001 \%$ pyronin-Y [w:v], 30 $\mathrm{mM}$ Tris- $\mathrm{HCl}[\mathrm{pH} 8.0]$ ) and 0.1 volumes of $\beta$-mercaptoethanol in the case of reduced samples or 0.1 volumes of extraction buffer in the case of nonreduced samples. Samples were heated for 15 min in a dry bath (approximately $50^{\circ} \mathrm{C}$ ) and then stored at $-80^{\circ} \mathrm{C}$ until analysis.

\section{One-dimensional SDS-PAGE}

Reduced and nonreduced sarcoplasmic protein samples were resolved using one-dimensional SDSPAGE. Western blotting revealed the relative quantities of multiple forms of Prdx-2. Precision Plus Dual Color Protein Standard (BioRad Laboratories, Hercules, CA) was run on each gel to determine the apparent molecular weight of proteins for all onedimensional gels. Gel running conditions and antibody dilutions for western blotting are provided in Table 1. Total Prdx-2 was quantified using $15 \%$ polyacrylamide separating gels $(10 \mathrm{~cm} \times 10 \mathrm{~cm}$; acrylamide: $\mathrm{N}, \mathrm{N}$-bismethylene acrylamide ratio of $100: 1[\mathrm{w}: \mathrm{w}], 0.1 \%$ [w:v] SDS, $0.05 \%[\mathrm{v}: \mathrm{v}]$ tetramethylenediamine [TEMED], $0.05 \%$ [w:v] ammonium persulfate [AMPER], and $0.5 \mathrm{M}$ Tris- $\mathrm{HCl}[\mathrm{pH} 8.8]$ ) with a $5 \%$ stacking gel (acryl-

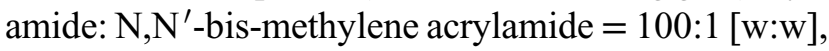
$0.1 \%$ [w:v] SDS, $0.125 \%$ TEMED, $0.075 \%$ [w:v] AMPER, and $0.125 \mathrm{M}$ Tris-HCl [pH 6.8]) with 10 running lanes. Gels were loaded with $60 \mu \mathrm{g}$ of reduced $(+\beta$-mercaptoethanol) protein sample per lane and run at ambient temperature at a constant voltage of $60 \mathrm{~V}$ for $360 \mathrm{~V}-\mathrm{h}$.

Prdx-2 posttranslational modifications and hyperoxidized peroxiredoxin content were compared using $12 \%$ polyacrylamide separating gels and $5 \%$ stacking gel. Nonreduced $(-\beta$-mercaptoethanol) protein $(60 \mu \mathrm{g})$ was loaded per lane and run at $4^{\circ} \mathrm{C}$ at a constant voltage of $30 \mathrm{~V}$ for approximately $540 \mathrm{~V}$-h.

Prdx-2 decamer content was determined using 5\% continuous gels (acrylamide: N, N'-bis-methylene acrylamide ratio of 100:1 [w: w], 0.1\% [w:v] SDS, $0.05 \%$ [v:v] TEMED, 0.05\% [w:v] AMPER, and $0.5 \mathrm{M}$ Tris- $\mathrm{HCl}$ [pH 8.8]) with 10 lanes. Eighty micrograms of nonreduced ( $-\beta$-mercaptoethanol) sarcoplasmic protein preparation was loaded per lane, and gels were run at $4{ }^{\circ} \mathrm{C}$ at a constant voltage of $20 \mathrm{~V}$ for approximately $750 \mathrm{~V}-\mathrm{h}$. SE 260 Hoefer Mighty Small II electrophoresis units (Hoefer, Inc., Holliston, MA) were used. The gel running buffer contained $25 \mathrm{mM}$ Tris, $192 \mathrm{mM}$ glycine, $2 \mathrm{mM}$ EDTA, and $0.1 \%$ [w:v] SDS.

\section{Gel transfer}

Gels for western blot analysis were transferred to polyvinylidene difluoride membranes with $0.2 \mu \mathrm{m}$ pore size (ISEQ00010, Immobilon-PS, Millipore Sigma, Darmstadt, Germany). The membranes were soaked in methanol before the transfer process for approximately $30 \mathrm{~s}$ and then equilibrated with transfer buffer (25 mM Tris, $192 \mathrm{mM}$ glycine, $2 \mathrm{mM}$ EDTA, and $15 \%$ [v:v] methanol). Proteins were transferred onto membranes using TE-22 Mighty Small units (Hoefer, Inc., Holliston, MA), running for a constant voltage of $90 \mathrm{~V}$ for $1.5 \mathrm{~h}$, in transfer buffer maintained at $4^{\circ} \mathrm{C}$.

\section{Western blotting}

Polyvinylidene difluoride membranes were blocked ( $1 \mathrm{~h}$ at room temperature) in a solution of PBS-Tween (80 mM Na $2 \mathrm{HPO}_{4}, 20 \mathrm{mM} \mathrm{NaH}{ }_{2} \mathrm{PO}_{4}$, 
$100 \mathrm{mM} \mathrm{NaCl}, 0.1 \%$ [v:v] polyoxyethylene sorbitan monolaurate [Tween-20]) containing 5\% non-fat dry milk. Primary antibodies diluted in PBS-Tween were added to the blot membranes and incubated for approximately $20 \mathrm{~h}$ at $4^{\circ} \mathrm{C}$.

A separate protocol using 2 primary antibodies allowed simultaneous detection and comparison of hyperoxidized peroxiredoxin to total nonreduced peroxiredoxin. In this way, hyperoxidized peroxiredoxin quantity was compared directly to the total Prdx-2 seen per lane/sample to develop a hyperoxidized band ratio relative to the total Prdx-2. Test western blots were run to ensure that the 2 antibodies did not interact with each other (Figure 1).

Following primary incubation, blots were washed for three 10-minute periods in PBS-Tween and incubated with secondary antibodies at ambient temperature for $1 \mathrm{~h}$. Antibody details are listed in Table 1.

After completion of secondary incubation, all blots were washed for three 10-minute periods in PBSTween. Proteins were detected with a commercial chemiluminescence kit (ECL Prime, GE Healthcare, Piscataway, NJ) with a 5-min incubation time. Images were produced and analyzed using a ChemiImager 5500 (Alpha Innotech, San Leandro, CA) and Alpha Ease FC software (version 3.03, Alpha Innotech). Individual protein bands were quantified for each sample using densitometry, and comparisons were made between single samples by taking the ratio of the measured protein band to a reference used in all blots. The reference sample was porcine sarcoplasmic protein from at-death muscle. Additional within-sample comparisons were made for Prdx-2 on nonreducing gels. Two distinct bands were seen when Prdx-2 was resolved on nonreducing gels.
The difference in migration could be due to posttranslational modification, most likely glutathionylation (Salzano et al., 2014). A ratio of the second, faster-migrating band relative to the total Prdx-2 seen in each lane was calculated.

GAPDH nonreducing gel western blot analyses were performed. One-dimensional electrophoresis and western blotting were conducted as previously discussed. Nonreduced protein $(60 \mu \mathrm{g})$ was loaded onto $15 \%$ acrylamide gels. Each sample was performed in duplicate.

\section{Carbonyl content assay}

Carbonyl content of sarcoplasmic proteins was determined according to Reznick and Packer (1994). All samples were run in triplicate. Samples from the sarcoplasmic protein fraction were diluted to $6 \mathrm{mg} / \mathrm{mL}$ concentration using $1 \mathrm{mM}$ EDTA, $50 \mathrm{mM} \mathrm{NaHPO}_{4}$ [pH 7.4] at $4{ }^{\circ} \mathrm{C}$. One milliliter of $6 \mathrm{mg} / \mathrm{mL}$ sample was incubated with $4 \mathrm{~mL}$ of $10 \mathrm{mM}$ 2,4-Dinitrophenylhydrazine (DNPH) in $2.5 \mathrm{M} \mathrm{HCl}$. A second sample $(1 \mathrm{~mL}$ of 6 $\mathrm{mg} / \mathrm{mL}$ ) was added to $4 \mathrm{~mL}$ of $2.5 \mathrm{M} \mathrm{HCl}$ served as a control. All samples were vortexed and incubated in the dark at $22^{\circ} \mathrm{C}$ for $30 \mathrm{~min}$, vortexed again, and incubated at the same temperature for an additional 30 min. After incubation, the reaction was stopped with the addition of $5 \mathrm{~mL}$ of $20 \%(\mathrm{w}: \mathrm{v})$ trichloroacetic acid, and the sample was placed in an ice bath for $10 \mathrm{~min}$ before being centrifuged at $3,100 \times g$ for $10 \mathrm{~min}$ at $4^{\circ}$ C (Sorvall Super T21, Newtown, CT). Following centrifugation, the supernatant was discarded, and the pellet was washed in $10 \%(\mathrm{w}: \mathrm{v})$ trichloroacetic acid before being vortexed and centrifuged at $3,100 \times g$ at $4^{\circ} \mathrm{C}$. The supernatant was again discarded, and the pellet was washed in a mixture of 1:1 ethyl acetate and ethanol (a)

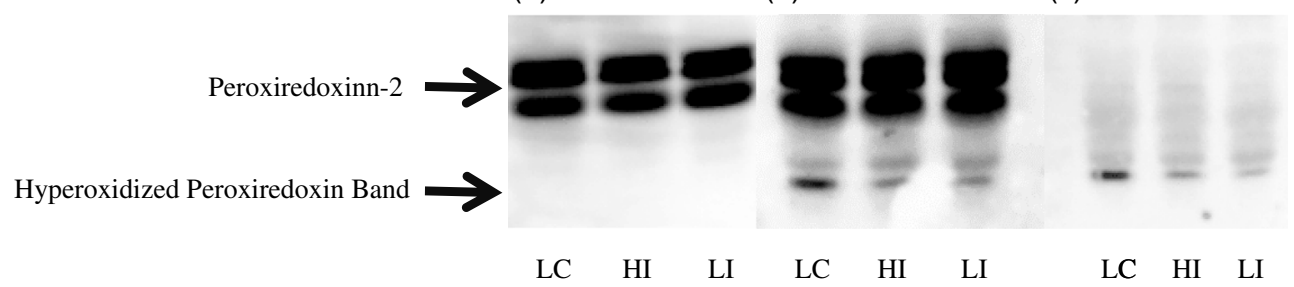

Figure 1. Two primary antibodies were used for the hyperoxidized peroxiredoxin analysis (peroxiredoxin-2 and hyperoxidized peroxiredoxin) on westerns from nonreducing gels. Hyperoxidized peroxiredoxin could be compared with an in-gel reference and the total peroxiredoxin-2 within a sample lane. In this way, hyperoxidized peroxiredoxin relative to peroxiredoxin-2 could be determined. Western blotting was performed to ensure no issue occurred as a result of using 2 primary antibodies. (A) was incubated a 1:10,000 dilution of peroxiredoxin-2 primary antibody (ab109367, Abcam, Cambridge, UK). (B) was incubated with a 1:2,000 dilution of hyperoxidized peroxiredoxin primary antibody (peroxiredoxin- $\mathrm{SO}_{3}$, ab16830, Abcam, Cambridge, UK) and a 1:10,000 dilution of peroxiredoxin-2 primary antibody (ab109367, Abcam, Cambridge, UK). (C) was incubated with only a 1:2,000 dilution of hyperoxidized peroxiredoxin primary antibody (peroxiredoxin- $\mathrm{SO}_{3}$, ab16830, Abcam, Cambridge, UK). Primary incubations were carried out for approximately $20 \mathrm{~h}$ at $4^{\circ} \mathrm{C}$. Following primary incubation, the same western blot protocols were carried out for blot washing, secondary incubation, and imaging. Samples are labeled based on their feed efficiency and infection status: Low RFI Control (LC), Low RFI Inoculated (LI), High RFI Control (HC), and High RFI Inoculated (HI). Samples are the same in each of the presented images. RFI, residual feed intake. 
Table 1. Protein fractions, gel loading conditions, acrylamide percentages, and antibody dilutions used to determine peroxiredoxin-2 profile, hyperoxidized peroxiredoxin, and glyceraldehyde 3-phosphate dehydrogenase relative content in samples

\begin{tabular}{|c|c|c|c|c|c|c|c|}
\hline Protein Measured & $\begin{array}{l}\text { Muscle } \\
\text { Fraction }\end{array}$ & $\begin{array}{l}\beta \text {-Mercaptoethanol } \\
\text { Presence/Absence }\end{array}$ & $\begin{array}{l}\text { Protein } \\
\text { Load }\end{array}$ & $\begin{array}{l}\text { Acrylamide } \\
\text { Percentage }^{1}\end{array}$ & Reference & $\begin{array}{l}\text { Primary Antibody } \\
\text { Dilution }^{2}\end{array}$ & $\begin{array}{l}\text { Secondary Antibody } \\
\text { Dilution }^{2}\end{array}$ \\
\hline $\begin{array}{l}\text { Total } \\
\text { Peroxiredoxin-2 }\end{array}$ & Sarcoplasmic & Present & $60 \mu \mathrm{g}$ & $15 \%$ & $\begin{array}{l}0 \mathrm{~d} \text { LD } \\
\text { (sarcoplasmic) }\end{array}$ & $1: 20,000$ & $1: 10,000 \mathrm{GAR}^{4}$ \\
\hline $\begin{array}{l}\text { Nonreducing Gel } \\
\text { Peroxiredoxin-2 }\end{array}$ & Sarcoplasmic & Absent & $60 \mu \mathrm{g}$ & $12 \%$ & $\begin{array}{l}0 \mathrm{~d} \text { LD } \\
\text { (sarcoplasmic) }\end{array}$ & $1: 15,000$ & $1: 10,000 \mathrm{GAR}^{4}$ \\
\hline $\begin{array}{l}\text { Peroxiredoxin-2 } \\
\text { Decamer }^{3}\end{array}$ & Sarcoplasmic & Absent & $80 \mu \mathrm{g}$ & $5 \%$ & $\begin{array}{l}0 \mathrm{~d} \text { LD } \\
\text { (sarcoplasmic) }\end{array}$ & $1: 10,000$ & $1: 5,000 \mathrm{GAR}^{4}$ \\
\hline $\begin{array}{l}\text { Hyperoxidized } \\
\text { Peroxiredoxin }\end{array}$ & Sarcoplasmic & Absent & $60 \mu \mathrm{g}$ & $12 \%$ & $\begin{array}{l}0 \mathrm{~d} \text { LD } \\
\text { (sarcoplasmic) }\end{array}$ & $1: 2,0001: 10,000^{5}$ & $1: 5,000 \mathrm{GAR}^{4}$ \\
\hline $\begin{array}{l}\text { Glyceraldehyde } \\
\text { 3-Phosphate } \\
\text { Dehydrogenase }^{6}\end{array}$ & Sarcoplasmic & Absent & $60 \mu \mathrm{g}$ & $15 \%$ & $\begin{array}{l}0 \mathrm{~d} \\
\text { semitendinosus: } \\
\text { Red portion } \\
\text { (sarcoplasmic) }\end{array}$ & $1: 10,000$ & $1: 10,000 \mathrm{GAM}^{7}$ \\
\hline
\end{tabular}

${ }^{1}$ Acrylamide/bis-acrylamide ratio 100:1 for separating and stacking (5\%); all analyses used 5\% stacking gel, excluding the peroxiredoxin-2 decamer test, which utilized a continuous $5 \%$ acrylamide gels.

${ }^{2}$ Primary and secondary antibody incubations were diluted in PBS-Tween solution $\left(80 \mathrm{mM} \mathrm{Na}_{2} \mathrm{HPO}_{4}, 20 \mathrm{mM} \mathrm{NaH}_{2} \mathrm{PO}_{4}, 100 \mathrm{mM} \mathrm{NaCl}, 0.1 \%\right.$ [v:v] polyoxyethylene sorbitan monolaurate [Tween-20]).

${ }^{3}$ Peroxiredoxin-2 primary antibody ab109367, Abcam, Cambridge, UK.

${ }^{4} \mathrm{GAR}=$ goat-anti rabbit-HRP antibody 31460 , Thermo Scientific, Rockford, IL.

${ }^{5}$ Two primary antibodies were used for the hyperoxidized peroxiredoxin analysis (peroxiredoxin-2 and hyperoxidized peroxiredoxin) so that hyperoxidized peroxiredoxin could be compared to an in-gel reference and the total peroxiredoxin- 2 within a sample lane. In this way, hyperoxidized peroxiredoxin relative to the total peroxiredoxin-2 pool could be determined. 1:2,000, hyperoxidized peroxiredoxin (peroxiredoxin-SO $\mathrm{S}_{3}$ ) ab16830, Abcam, Cambridge, UK. 1:10,000 peroxiredoxin-2 primary antibody ab109367, Abcam, Cambridge, UK.

${ }^{6}$ Glyceraldehyde 3-phosphate dehydrogenase primary antibody- MAB374, Millipore, Massachusetts, MA.

${ }^{7} \mathrm{GAM}=$ goat-anti mouse-HRP antibody- A2554, Sigma Aldrich, Darmstadt, Germany.

(v:v), vortexed, and centrifuged for $10 \min (3,100 \times g$ at $\left.4^{\circ} \mathrm{C}\right)$. This step was repeated once. The supernatant was discarded, and the pellet was placed $2 \mathrm{~mL}$ of $6 \mathrm{M}$ guanidine hydrochloride $\left(\mathrm{H}_{2} \mathrm{NC}(\mathrm{NH}) \mathrm{NH}_{2}\right) \quad(\mathrm{pH} \quad 2.0)$. Samples were vigorously vortexed and placed in a $37^{\circ}$ $\mathrm{C}$ water bath for $5 \mathrm{~min}$. This step was repeated twice. After the pellet was solubilized, the solution was centrifuged at $3,700 \times g$ for $10 \mathrm{~min}$ at $20^{\circ} \mathrm{C}$. All DNPH-treated samples were read using an Ultrospec 3000 spectrophotometer (Pharmacia Biotech, Piscataway, NJ) at $365 \mathrm{~nm}$. Protein content was determined from control (no DNPH) samples using a Bradford assay (BioRad Laboratories, Hercules, CA). Total carbonyl content was determined using the molecular extinction coefficient of $10 \mathrm{mM}$ DNPH $\left(22,000 / \mathrm{M}=22,000 / 10^{6} \mathrm{nmol} / \mathrm{mL}\right)$.

\section{Diagonal gel electrophoresis}

Diagonal gel electrophoresis was used to examine relative differences in disulfide protein content between samples, according to Kim et al. (2010), with some modifications. In the first dimension, nonreduced sarcoplasmic protein samples $(4 \mathrm{mg} / \mathrm{mL})$ were prepared without $\beta$-mercaptoethanol, as previously described, and $1.14 \mathrm{mg}$ protein was loaded onto a 10 $\mathrm{cm} \times 10 \mathrm{~cm} 12 \%$ polyacrylamide gel with a single 8.5 -cm-wide lane. Gels were run at $4^{\circ} \mathrm{C}$ at a constant voltage of $20 \mathrm{~V}$ for approximately $560 \mathrm{~V}-\mathrm{h}$. Nonreduced (first dimension) gels were incubated for $1 \mathrm{~h}$ at ambient temperature in a reducing SDS buffer (4\% [w:v] SDS, 125 Mm Tris-HCl, 20\% [v:v] glycerol, $0.04 \%$ [w:v] bromophenol blue [pH 6.8]) containing $0.2 \% \beta$-mercaptoethanol. A 1 -cm-wide section was excised after incubation from the gel's center and fixed with agarose to a second $15 \%$ polyacrylamide gel. The gel was run at ambient temperature at a constant voltage of $60 \mathrm{~V}$ for $360 \mathrm{~V}-\mathrm{h}$ for the second dimension; $0.1 \% \beta$-mercaptoethanol was included in the second dimension running buffer. Gels were stained overnight in a Colloidal Coomassie Blue Stain. Stained gels were rinsed multiple times in distilled deionized water to remove any residual stain. Gels were visually appraised to compare differences in spots appearing below the diagonal line of proteins. These spots appearing below the line were the result of intermolecular disulfide bonds being broken through the reducing process (Winger et al., 2007). Gels were run in duplicate. Four spots were selected for identification based on 
the diagonal gel analysis. Spots were excised and sent to the Proteomics Facility at Iowa State University for liquid chromatography-mass spectrometry identification (Stewart, 1999).

\section{Statistical analysis}

A $2 \times 2$ factorial design was used to evaluate the fixed effects of line (HRFI and LRFI), challenge status (control and infected), and their interaction. The MIXED procedure of SAS (version 9.4; SAS Institute Inc., Cary, NC) was used to analyze these data. Day of necropsy and gel repetition (for western blot analysis) were included as random effects. Litter nested within line was considered as a random effect but was not included in the final analysis when it was not significant. Differences were considered significant when $P \leq 0.05$, and tendencies were considered when $0.05<P \leq 0.10$.

\section{Results and Discussion}

\section{Health-challenge response and growth performance}

Details on the growth performance of the pigs used in this study are reported in Helm et al. (2018b). The performance results are summarized here to provide context for the current results. Briefly, in the $21 \mathrm{~d}$ following inoculation, health-challenged pigs from both RFI lines demonstrated reduced ADG $(38 \%, P<$ $0.0001)$, ADFI $(25 \%, P<0.0001)$, and G:F $(19 \%$, $P=0.014)$ compared with nonchallenged controls (Helm et al., 2018b). This study's results demonstrate the negative impact of subclinical bacterial infections such as L. intracellularis and M. hyopneumoniae on growth performance (Helm et al., 2018b). The interaction between line and infection status was not significant for growth performance traits (Helm et al., 2018b). These observations were consistent with previous data, as differences between these lines have not been identified in other studies that examined growth traits in response to a pathogenic challenge (Dunkelberger et al., 2015; Helm et al., 2018a). Merlot et al. (2016), for example, did not identify differences to an inflammatory health challenge between the INRA divergently selected RFI lines.

\section{Protein oxidation}

Various biological factors play a role in differences in efficiency between animals that differ in RFI. These factors include feeding patterns, body composition, heat increment, activity, digestibility, protein turnover, tissue metabolism, and oxidative stress (Richardson and Herd, 2004). Oxidative stress in living tissue can be defined as an imbalance between prooxidant and antioxidant forces in favor of prooxidants (Sies et al., 2017). These prooxidants include ROS that are produced through a wide array of reactions within the cellular environment. ROS are thought to play a role in differences in efficiency between animals of differing RFI (Bottje et al., 2002; Grubbs et al., 2013a).

Grubbs et al. (2013a) studied ROS production from mitochondria from the skeletal muscle of the Iowa State University HRFI and LRFI lines. They found that more efficient LRFI pigs tended to have less ROS production in the isolated mitochondria of both red and white semitendinosus skeletal muscle tissue. They also reported positive correlations between RFI and ROS production from mitochondria of longissimus skeletal muscle. Using pigs from the same selection lines, Helm et al. (2018b) demonstrated no RFI line effects for ROS production by mitochondria in the longissimus muscle, but did show a tendency for greater ROS production in longissimus mitochondria in response to MhLI. Bottje et al. (2006) found that the skeletal muscle mitochondria of broilers with poor feed efficiency had greater ROS production and electron leakage and were prone to increased protein oxidation measured through protein carbonylation. Health challenges may increase oxidative stress. This is possibly due to increased production and leakage of ROS from the mitochondria as a result of increased energy demand to combat challenges (Deblanc et al., 2013; Sies et al., 2017).

Oxidation of sarcoplasmic proteins from longissimus muscle samples was analyzed using DNPH-based carbonyl quantification and diagonal gel electrophoresis. Protein carbonyl quantification is a method of measuring irreversible protein oxidation of amino acids (Reznick and Packer, 1994). These damaged amino acids are energetically expensive because they must be removed and replaced if protein function is to be maintained. A unique tool that can be used to evaluate protein oxidation and provide information regarding oxidation-induced protein interaction is diagonal gel electrophoresis. Diagonal gel electrophoresis assesses reversible protein oxidation by providing information about potential disulfide bonds between proteins (Winger et al., 2007).

Neither infection status nor RFI line significantly affected protein carbonylation in the sarcoplasmic protein extract of longissimus skeletal muscle (Table 2). The lack of a significant difference may be because this 
Table 2. Least-squares means for main effects of residual feed intake (RFI) line (low RFI [LRFI], high RFI [HRFI]), infection status, and of the interaction of RFI line and infection status on peroxiredoxin-2 (Prdx-2) features, glyceraldehyde 3-phosphate dehydrogenase (GAPDH), and carbonyl content for the sarcoplasmic protein fraction of the longissimus skeletal muscle

\begin{tabular}{|c|c|c|c|c|c|c|c|c|}
\hline \multirow[b]{2}{*}{ Trait } & \multicolumn{5}{|c|}{ Treatment } & \multicolumn{3}{|c|}{$P$ Value } \\
\hline & LRFI & HRFI & Control & $\mathrm{MhLI}^{1}$ & SEM & RFI Line & Infection Status & $\begin{array}{c}\text { RFI Line } \times \\
\text { Infection Status }\end{array}$ \\
\hline$N$ & 12 & 12 & 12 & 12 & & & & \\
\hline Total Prdx-2 ${ }^{2}$ & 0.58 & 0.67 & 0.60 & 0.65 & 0.049 & 0.035 & 0.269 & 0.893 \\
\hline Prdx-2 Decamer ${ }^{2}$ & 0.59 & 0.97 & 0.73 & 0.82 & 0.072 & 0.0007 & 0.418 & 0.983 \\
\hline Prdx-2 Nonreducing Gel 1st Band ${ }^{2}$ & 0.93 & 1.02 & 1.01 & 0.94 & 0.034 & 0.055 & 0.131 & 0.063 \\
\hline Prdx-2 Nonreducing Gel 2nd Band ${ }^{2}$ & 0.89 & 1.07 & 0.97 & 0.99 & 0.036 & 0.0006 & 0.620 & 0.277 \\
\hline $\begin{array}{l}\text { Prdx-2 Nonreducing Gel Within } \\
\text { Sample Comparison }\end{array}$ & 0.49 & 0.50 & 0.48 & 0.51 & 0.009 & 0.757 & 0.014 & 0.020 \\
\hline Hyperoxidized Peroxiredoxin ${ }^{2}$ & 0.78 & 0.76 & 0.79 & 0.74 & 0.062 & 0.779 & 0.561 & 0.088 \\
\hline Hyperoxidized Prdx Comparison ${ }^{4}$ & 0.48 & 0.42 & 0.44 & 0.45 & 0.022 & 0.028 & 0.679 & 0.056 \\
\hline Carbonyl Content, nM/mg Protein & 8.39 & 8.65 & 8.48 & 8.58 & 0.959 & 0.801 & 0.923 & 0.064 \\
\hline GAPDH Nonreducing Gel ${ }^{2}$ & 0.69 & 0.66 & 0.49 & 0.85 & 0.120 & 0.817 & 0.017 & 0.083 \\
\hline
\end{tabular}

Significant statistical differences $(P \leq 0.05)$ are bolded. Statistical trends $(0.10>P>0.05)$ are italicized

${ }^{1} \mathrm{MhLI}=$ Mycoplasma hyopneumoniae and Lawsonia intracellularis

${ }^{2}$ Relative protein content was determined using western blotting by comparing the densitometry of sample protein bands to a reference sample of $0 \mathrm{~d}$ aged sarcoplasmic extract protein sample. Thus, the observed data are a ratio of sample to reference.

${ }^{3}$ Comparisons were made through a ratio of the second, faster-migrating protein band and all immunoreactive protein in sample lane.

${ }^{4}$ Comparisons were made between hyperoxidized peroxiredoxin and all immunoreactive protein in sample lane.

health challenge may have induced only a low level of oxidative stress initiated by this health challenge, possibly due to its subclinical nature. It could also be partially explained by the fact that neither of the pathogens used in this project directly target skeletal muscle. Interestingly, a trend was seen for an interaction between RFI line and infection status $(P=0.064)$, with carbonyl content being greater in LRFI MhLI pigs than LRFI control pigs and lower in HRFI MhLI pigs compared with HRFI controls (Table 3). This suggests subtle differences in how animals of differing feed efficiency respond to oxidative stress.

When sarcoplasmic proteins were evaluated using diagonal electrophoresis, there were 4 protein spots appearing below the diagonal line of proteins that were selected for identification using liquid chromatography-mass spectrometry. Appearance of these proteins below the diagonal line of proteins indicates that those proteins were likely crosslinked via intermolecular disulfide bonds. Individual peptides identified in each spot are listed in Table 4. Two of the spots were identified as creatine kinase, and 2 were identified as GAPDH (Figure 2). GAPDH was chosen to analyze further using western blotting. Relative GAPDH content was analyzed using western blotting on onedimensional SDS-PAGE gels under reducing and nonreducing gel conditions (Figure 3 ).
Infection status and RFI line both appeared to influence GAPDH oxidation. This is particularly interesting as GAPDH is an essential catalyst in the glycolysis pathway. GAPDH has recently become a protein of interest with respect to metabolic and redox regulation (Hildebrandt et al., 2015; Peralta et al., 2015; Araki et al., 2016). GAPDH is particularly sensitive to oxidation by $\mathrm{H}_{2} \mathrm{O}_{2}$ and has been identified as one of its most prominent protein targets (Baty et al., 2005; Hancock et al., 2005). Its cysteine groups react more quickly with $\mathrm{H}_{2} \mathrm{O}_{2}$ than free cysteines, glutathione, and most other redox-regulated proteins. However, its reaction rate is still slower than that seen in $\mathrm{H}_{2} \mathrm{O}_{2}$-targeting antioxidant proteins such as Prdx-2 (Winterbourn and Hampton, 2008).

When the sarcoplasmic proteins were reduced, no treatment or line differences were detected in GAPDH content using western blotting. However, under nonreducing conditions (Figure 3A), a significant increase in a more slowly migrating band (Band 1) of GAPDH was seen in MhLI animals compared with control animals $(P=0.017)$ across RFI line. Moreover, there was suggestive evidence of an interaction between line and health status $(P=0.083)$ for this more slowly migrating band (Table 2); a significant difference existed between the control and MhLI pigs in the HRFI line, with MhLI pigs having a greater amount of the more slowly migrating band $(P=0.0025)$, but not in the LRFI line (Table 3 ). 
Table 3. Least-squares means for RFI line $\times$ infection interactions of RFI line (LRFI, HRFI), infection status (control, MhLI), and interactions of RFI line and infection status on Prdx-2 features, GAPDH, and carbonyl content for the sarcoplasmic protein fraction of the longissimus skeletal muscle for RFI line $\times$ infection status

\begin{tabular}{|c|c|c|c|c|c|c|c|c|}
\hline \multirow[b]{2}{*}{ Trait } & \multicolumn{4}{|c|}{ Treatment } & \multicolumn{4}{|c|}{$P$ Value } \\
\hline & LRFI Control & HRFI Control & LRFI MhLI & HRFI MhLI & SEM & RFI Line & Infection Status & $\begin{array}{c}\text { RFI Line } \times \\
\text { Infection Status }\end{array}$ \\
\hline$n$ & 6 & 6 & 6 & 6 & & & & \\
\hline $\begin{array}{l}\text { Prdx-2 Nonreducing Gel } \\
\text { 1st Band }\end{array}$ & $0.91^{\mathrm{a}}$ & $1.10^{\mathrm{b}}$ & $0.94^{\mathrm{a}}$ & $0.94^{\mathrm{a}}$ & 0.047 & 0.055 & 0.131 & 0.063 \\
\hline $\begin{array}{l}\text { Prdx-2 Nonreducing Gel } \\
\text { Within Sample } \\
\text { Comparison }^{2}\end{array}$ & $0.49^{\mathrm{a}}$ & $0.48^{\mathrm{a}}$ & $0.50^{\mathrm{ab}}$ & $0.52^{\mathrm{b}}$ & 0.011 & 0.757 & 0.014 & 0.020 \\
\hline $\begin{array}{l}\text { Hyperoxidized } \\
\text { Peroxiredoxin }^{1}\end{array}$ & $0.89^{\mathrm{a}}$ & $0.71^{\mathrm{a}}$ & $0.68^{\mathrm{a}}$ & $0.81^{\mathrm{a}}$ & 0.087 & 0.779 & 0.561 & 0.088 \\
\hline $\begin{array}{l}\text { Hyperoxidized Prdx } \\
\text { Comparison }^{3}\end{array}$ & $0.50^{\mathrm{a}}$ & $0.39^{\mathrm{b}}$ & $0.46^{\mathrm{ab}}$ & $045^{\mathrm{ab}}$ & 0.029 & 0.028 & 0.679 & 0.056 \\
\hline Carbonyl Content, nM/mg Protein & $7.34^{\mathrm{a}}$ & $9.61^{\mathrm{a}}$ & $9.44^{\mathrm{a}}$ & $7.71^{\mathrm{a}}$ & 1.16 & 0.801 & 0.923 & 0.064 \\
\hline GAPDH Nonreducing Gel $^{1}$ & $0.64^{\mathrm{ab}}$ & $0.35^{\mathrm{a}}$ & $0.74^{\mathrm{ab}}$ & $0.96^{\mathrm{b}}$ & 0.159 & 0.817 & 0.017 & 0.083 \\
\hline
\end{tabular}

Significant statistical differences $(P \leq 0.05)$ are bolded. Statistical trends $(0.10>P>0.05)$ are italicized.

${ }^{1}$ Relative protein content was determined using western blotting by comparing the densitometry of sample protein bands to a reference sample of 0 -d-aged sarcoplasmic extract protein sample. Thus, the observed data are a ratio of sample to reference.

${ }^{2}$ Comparisons were made through a ratio of the second, faster-migrating protein band and all immunoreactive protein in sample lane.

${ }^{3}$ Comparisons were made between hyperoxidized peroxiredoxin and all immunoreactive protein in sample lane.

${ }^{\mathrm{a}-\mathrm{c}}$ Means with differing subscripts in the same row indicate a significant difference $(P \leq 0.05)$.

GAPDH = glyceraldehyde 3-phosphate dehydrogenase; HRFI = High RFI; LRFI = Low RFI; MhLI = Mycoplasma hyopneumoniae and Lawsonia intracellularis; Prdx-2 = peroxiredoxin-2; RFI = residual feed intake; SEM = standard error of the mean.

The nonreducing gels showed an increased abundance of the slower-migrating band of GAPDH in muscle from MhLI pigs. This was likely the result of an oxidative modification to the protein. The reactive cysteines in GAPDH are susceptible to multiple oxidation modifications, including sulfenic, sulfinic,

Table 4. Protein spots identified from diagonal gel electrophoresis with individual peptides and Mowse Scores

\begin{tabular}{|c|c|c|c|c|c|c|}
\hline Spot Number & Protein ID & Species & Accession Number & Coverage $^{1}$ & Peptides & Mowse Score \\
\hline Spot 3 & Creatine kinase & Sus scrofa & Q5XLD3 & $52.23 \%$ & $\begin{array}{l}\text { FCVGLQK } \\
\text { GGDDLDPNYVLSSR } \\
\text { LNFKAEEEYPDLSK } \\
\text { ALTLEIYKK } \\
\text { FEEILTR } \\
\text { SFLVWVNEEDHLR } \\
\text { LSVEALNSLTGEFK } \\
\text { DLFDPIIQDR } \\
\text { LGSSEVEQVQLVVDGVK } \\
\text { GTGGVDTAAVGSVFDVSNADR } \\
\text { RGTGGVDTAAVGSVFDVSNADR } \\
\text { ALTLEIYK } \\
\text { GYTLPPHCSR } \\
\text { GIWHNDNK } \\
\text { TDLNHENLK } \\
\text { LMVEMEK } \\
\text { HKTDLNHENLK } \\
\text { GQSIDDMIPAQK } \\
\text { AEEEYPDLSK } \\
\text { GQSIDDMIPAQK } \\
\text { PFGNTHNK } \\
\text { IEEIFKK } \\
\text { HGGYKPTDK }\end{array}$ & 6928 \\
\hline
\end{tabular}


Table 4. (Continued)

\begin{tabular}{|c|c|c|c|c|c|c|}
\hline Spot Number & Protein ID & Species & Accession Number & Coverage $^{1}$ & Peptides & Mowse Score $^{2}$ \\
\hline Spot 4 & Creatine kinase & Sus scrofa & Q5XLD3 & $33.59 \%$ & $\begin{array}{l}\text { GTGGVDTAAVGSVFDVSNADR } \\
\text { RGTGGVDTAAVGSVFDVSNADR } \\
\text { LGSSEVEQVQLVVDGVK } \\
\text { DLFDPIIQDR } \\
\text { LSVEALNSLTGEFK } \\
\text { SFLVWVNEEDHLR } \\
\text { GGDDLDPNYVISSR } \\
\text { TDLNHENLK } \\
\text { GQSIDDMIPAQK } \\
\text { AEEEYPDLSK } \\
\text { FCVGLQK }\end{array}$ & 4332 \\
\hline Spot 1 & $\begin{array}{l}\text { Glyceraldehyde- } \\
\text { 3-phosphate } \\
\text { dehydrogenase }\end{array}$ & Sus scrofa & P00355 & $48.05 \%$ & $\begin{array}{l}\text { TVDGPSAKLWR } \\
\text { IVSNASCTTNCLAPIAK } \\
\text { LTGMAFR } \\
\text { LEKPAKYDDIK } \\
\text { VGVNGFGR } \\
\text { VGVNGFGR } \\
\text { VVDLMVHMASKE } \\
\text { VVDLMVHMASK }\end{array}$ & 5678 \\
\hline Spot 2 & $\begin{array}{l}\text { Glyceraldehyde- } \\
\text { 3-phosphate } \\
\text { dehydrogenase }\end{array}$ & Sus scrofa & P00355 & $48.65 \%$ & $\begin{array}{l}\text { TVDGPSGK } \\
\text { IVSNASCTTNCLAPLAK } \\
\text { GAAQNIIPASTGAAKAVGK } \\
\text { AITIFQER } \\
\text { LISWYDNEFGYSNR } \\
\text { RVIISAPSADAPMFVMGVNHEK } \\
\text { AITIFQERDPANIK } \\
\text { VIISAPSADAPMFVMGVNHEK } \\
\text { VPTPNVSVVDLTCR } \\
\text { LTGMAFR } \\
\text { AENGKLVINGK } \\
\text { QASEGPLK } \\
\text { VIPELNGK } \\
\text { GAAQNIIPASTGAAK } \\
\text { VGVNGFGR } \\
\text { VVDLMVHMASKE } \\
\text { VVDLMVHMASK } \\
\text { VGVNGFGR }\end{array}$ & 9302 \\
\hline
\end{tabular}

\footnotetext{
${ }^{1}$ Percentage of the MASCOT protein sequence covered by identified matching peptides from trypsin digest.

${ }^{2}$ MOWSE $=$ molecular weight search, score used to calculate the similarity in molecular weight of the peptides from trypsin digest and the proteins from the MASCOT database.
}

sulfonic acid formation, S-glutathionylation, S-nitrosylation, and S-sulfhydration (Hildebrandt et al., 2015). The MhLI challenge may have caused enough of an increase in ROS production to oxidize the more $\mathrm{H}_{2} \mathrm{O}_{2}$-oxidation-susceptible GAPDH but not so much as to create a major change in overall protein carbonylation, which has implications in terms of antioxidant response and protein oxidation.

Oxidation of GAPDH cysteine active sites leads to a decrease in the glycolysis pathway and increased activation of the pentose phosphate pathway. This leads to increased reduction of the antioxidant glutathione through the action of glutathione reductase (Kuehne et al., 2015). This increased reductive capacity of glutathione may result in an overall reductive effect within the surrounding tissues, thus helping to mitigate ROSinduced damage (Figure 4).

\section{Peroxiredoxin-2 profile}

We hypothesized that differences would exist in the Prdx-2 profile based on RFI line and infection status. Peroxiredoxins are antioxidant proteins that convert $\mathrm{H}_{2} \mathrm{O}_{2}$ and other hydroperoxides to more stable compounds such as water. Peroxiredoxins are a unique family of proteins that also play a substantial role in cellular redox signaling. The peroxiredoxins have a greater content in tissues than other major antioxidants such as glutathione peroxidase and catalase (Ghaemmaghami et al., 2003) and have similar reactivity rates (Peskin et al., 2007).

Prdx-2 is a typical 2-cys peroxiredoxin present in all mammalian tissues (Leyens et al., 2003). It can exist in multiple oxidation states and differing oligomeric structures based on oxidative stress level and function. Prdx-2's role in response to oxidative stress challenge 


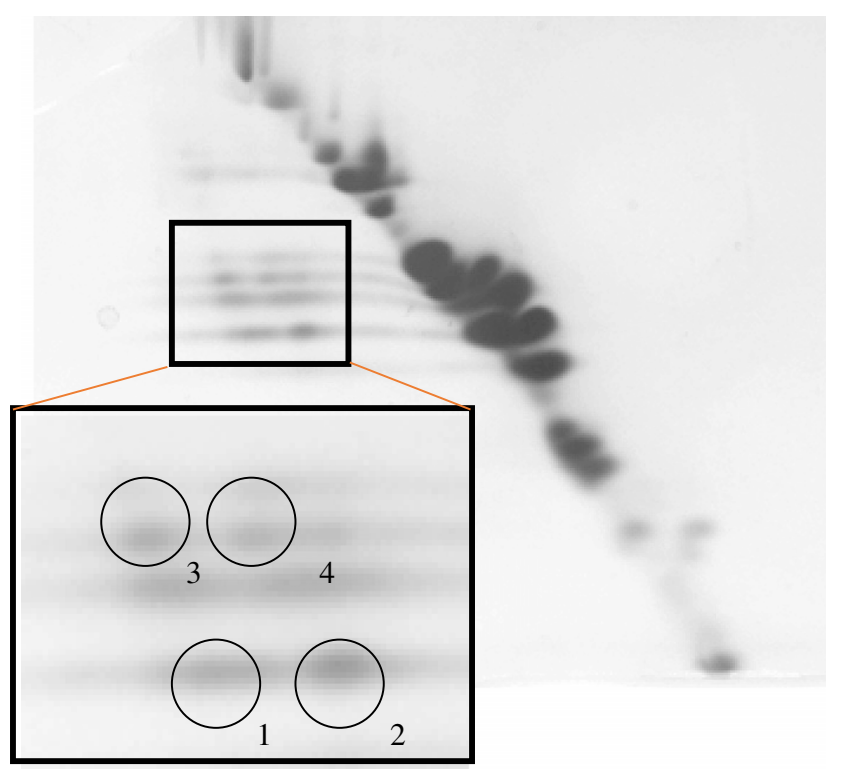

Figure 2. Representative diagonal gel electrophoresis image. A greater amount of protein spots were seen below the diagonal in the lowRFI samples than high-RFI counterparts. The 4 marked protein spots were selected for identification using liquid chromatography mass spectrometry (LC-MS). Spots 1 and 2 were both identified as glyceraldehyde 3-phosphate dehydrogenase. Spots 3 and 4 were identified as creatine kinase. Glyceraldehyde 3-phosphate dehydrogenase was selected for further analysis using western blot analysis. RFI, residual feed intake.

is well documented in human medicine in a wide variety of instances.

The Prdx-2 profile differs in response to a variety of oxidative stressors in pigs, including environmental heat stress (Cruzen et al., 2015), LPS-induced immune challenge (Outhouse et al., 2015), physiological stress (Marco-Ramell et al., 2016), and health challenge (Genini et al., 2012). Responses to these stresses include an increase in total Prdx-2, hyperoxidized
Prdx-2, and potentially an increase in larger stacked decamers of hyperoxidized Prdx-2. Differences in the Prdx-2 profile in response to a wide variety of stress challenges suggest an essential role of Prdx-2 in maintaining redox balance in livestock species. In the current study, RFI line and challenge status impacted the Prdx-2 profile, as revealed by western blot analysis of the sarcoplasmic protein fraction (Table 2 and Figure 5). Peroxiredoxins can be upregulated in response to an oxidative challenge to mitigate oxidative damage (Chang et al., 2007). The greater total Prdx-2 in the skeletal muscle of less efficient HRFI compared with LRFI pigs may be a response to the greater mitochondrial ROS leakage previously seen in HRFI animals (Grubbs et al., 2013a).

Grubbs et al. (2013b) observed that the antioxidant protein catalase was more abundant in mitochondria isolated from the muscle of HRFI compared with LRFI pigs. Chronic ROS exposure may lead to greater Prdx-2 production to prevent tissue damage and may indicate long-term oxidative stress. Greater ROS production and abundance of Prdx-2 indicate more oxidative stress in the muscle of HRFI pigs. That stress may help to explain the poorer efficiency in HRFI animals as there may be an increased diversion of nutrients that could be used for growth toward antioxidant protein production in addition to oxidized tissue repair.

Prdx-2 is an obligate dimer. However, the antioxidant protein can form a more complex decamer structure that is composed of 5 dimer subunits that interact through their $\beta$-strands (Karplus, 2015). This process is dependent upon the Prdx-2 oxidation state. Prdx-2 exists in 3 reactive cysteine oxidation states: reduced, oxidized, and hyperoxidized. In the reduced form

(a)

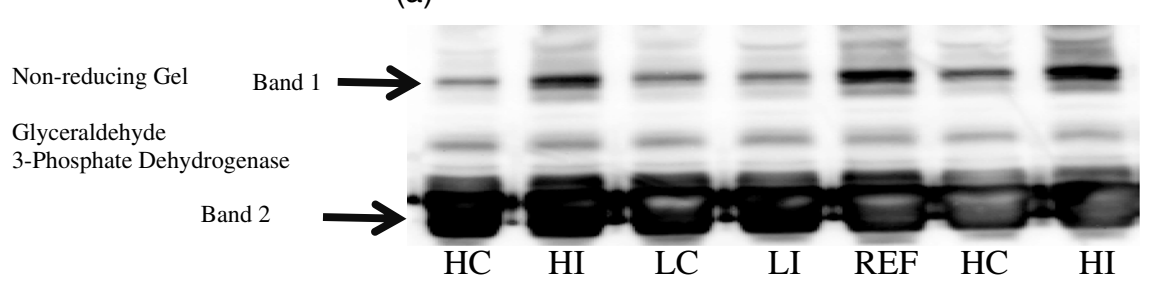

(b)
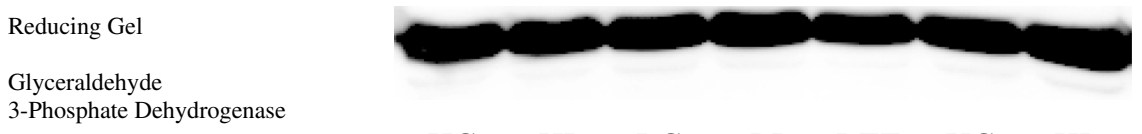

HC HI LC LI REF HC HI

Figure 3. Representative western blot of glyceraldehyde 3-phosphate dehydrogenase run on a (A) nonreducing gel and a (B) reducing gel from sarcoplasmic protein extracts of longissimus muscle collected immediately the following necropsy. Glyceraldehyde 3-phosphate dehydrogenase in samples was compared with a sarcoplasmic protein extract from an unaged longissimus sample (REF). Samples are labeled based on their feed efficiency and infection status: Low RFI Control (LC), Low RFI Inoculated (LI), High RFI Control (HC), and High RFI Inoculated (HI). RFI, residual feed intake. 
Metabolic Steady State

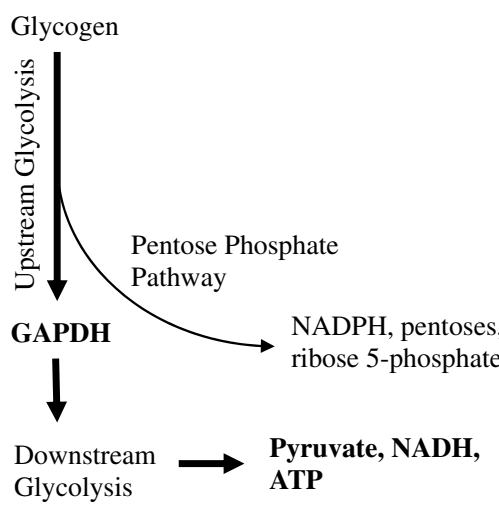

Increased glycolysis
Increased Oxidative Stress

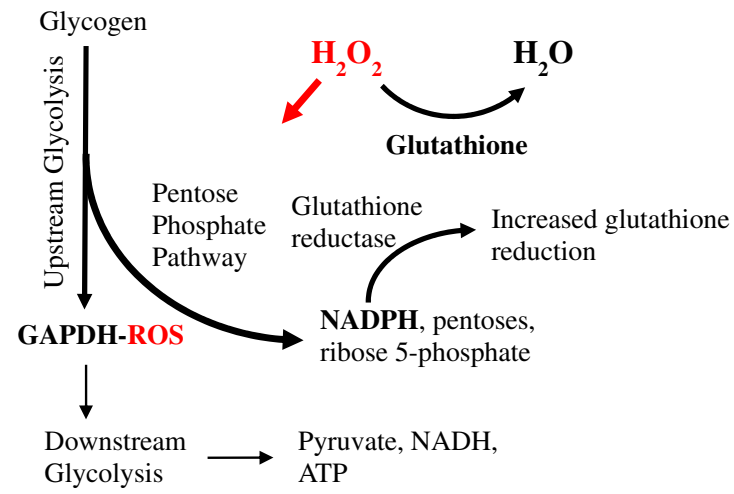

Increased pentose phosphate pathway, NADPH production, and glutathione reduction

Figure 4. Visual depiction of the shift from glycolysis toward the pentose phosphate pathway mediated through the oxidation of glyceraldehyde 3-phosphate dehydrogenase (GAPDH) during periods of increased oxidative stress and hydrogen peroxide $\left(\mathrm{H}_{2} \mathrm{O}_{2}\right)$ production. This shift toward the pentose phosphate pathway increases NADPH production, leading to an increase in glutathione reduction through the action of glutathione reductase. This increase in reduced glutathione concentration may, in turn, lead to increased reductive capacity, preventing increased protein oxidation. Figure adapted from Kuehne et al. (2015).

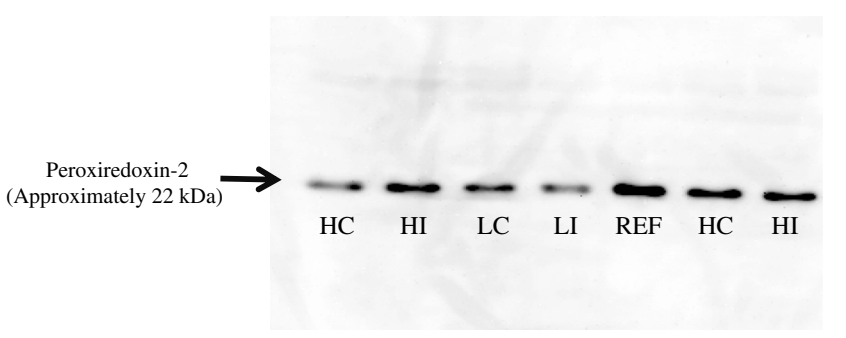

Figure 5. Representative western blot of total peroxiredoxin-2 resolved on a reducing gel. Samples were sarcoplasmic protein extracts from the longissimus muscle collected immediately following necropsy. All samples were compared with a sarcoplasmic protein extract from an unaged longissimus sample (REF). Samples are labeled based on their feed efficiency and infection status: Low RFI Control (LC), Low RFI Inoculated (LI), High RFI Control (HC), and High RFI Inoculated (HI).

(S-H), Prdx-2 is readily able to bind $\mathrm{H}_{2} \mathrm{O}_{2}$ to exert its peroxidation reaction. Through this reaction, Prdx-2 will convert $\mathrm{H}_{2} \mathrm{O}_{2}$ into a more stable water molecule $\left(\mathrm{H}_{2} \mathrm{O}\right)$, resulting in a sulfenic acid $(\mathrm{S}-\mathrm{OH})$ at the reactive cysteine site of Prdx-2. A reduced cysteine on the adjacent Prdx-2 in the same dimer will then form a disulfide bond with the sulfenic acid, releasing a single water molecule and creating an oxidized Prdx-2 (Karplus, 2015). Under normal circumstances, a thiol protein in the cell will break the oxidized Prdx-2 disulfide bond enabling it to return to its reactive reduced state. However, under conditions of greater oxidative stress and higher $\mathrm{H}_{2} \mathrm{O}_{2}$ concentrations, the sulfenic acid in $\operatorname{Prdx}-2$ may interact with another $\mathrm{H}_{2} \mathrm{O}_{2}$ molecule before disulfide formation resulting in the release of a water molecule and the formation of hyperoxidized Prdx-2 with a sulfinic acid group $\left(\mathrm{SO}_{2} \mathrm{H}\right)$. The hyperoxidized Prdx-2 is trapped in this nonreactive form until it is returned to the reduced form by an ATPdependent reaction catalyzed by a sulfiredoxin enzyme (Karplus, 2015).

Oxidation state heavily influences Prdx-2 decamer formation. A greater abundance of reduced Prdx-2 leads to increased decamer formation (Wood et al., 2003). Greater abundance of hyperoxidized Prdx-2 is also known to contribute to decamer formation. In some instances, hyperoxidized decamers will again come together to form larger stacked structures, which may play a role in cell signaling (Schröder et al., 2000; Dietz et al., 2006). Oxidized (disulfide bond) Prdx-2 exists preferentially in the dimer form. This is thought to be caused by Prdx-2 active site conformational changes surrounding the reactive cysteine through the Prdx-2 catalytic cycle. The partially unfolded conformation triggered by oxidation and disulfide formation is thought to weaken the interaction of the $\beta$-strands needed for decamer formation, leading to its disassembly. Prdx-2 will switch from decamer to dimer conformation as it progresses through its catalytic cycle (Flohe and Harris, 2007). With this in mind, greater Prdx-2 decamer formation can suggest a greater 


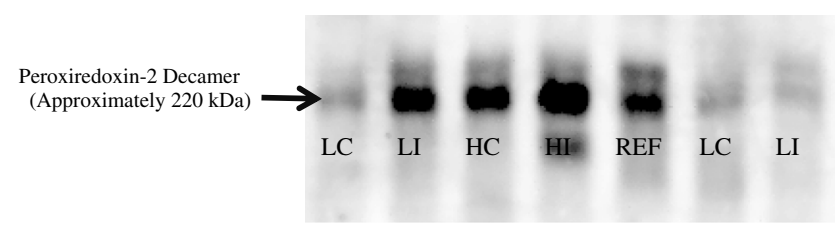

Figure 6. Representative western blot of the peroxiredoxin-2 decamer resolved on a nonreducing gel. Samples were sarcoplasmic protein extracts from the longissimus muscle collected immediately following necropsy. All samples were compared with a sarcoplasmic protein fraction from an unaged longissimus sample (REF). Samples are labeled based on their feed efficiency and infection status: Low RFI Control (LC), Low RFI Inoculated (LI), High RFI Control (HC), and High RFI Inoculated (HI).

amount of either active reduced $\operatorname{Prdx}-2$ or inactive hyperoxidized Prdx-2.

There was less of the Prdx-2 decamer in the skeletal muscle of LRFI pigs $(P=0.0007)$ compared with their HRFI counterparts, although the hyperoxidized peroxiredoxin content was similar between the 2 lines (Figure 6). There was no significant effect on Prdx-2 decamer amount of infection status or of the RFI line $x$ infection status interaction. This suggests that a greater amount of Prdx-2 is being kept in the reduced form in the muscle of HRFI pigs regardless of challenge.

Western blot analysis using nonreducing gels revealed Prdx-2 posttranslational modifications (Figure 7). Two protein bands of Prdx-2 were seen using this method. These bands were measured independently by comparison to a reference sample and also by determining a ratio of the second, faster-migrating band to the total Prdx-2 per sample lane. Neither line nor treatment had a significant effect on the abundance of slower-migrating Prdx-2 band resolved on the nonreducing gel western blot. However, a trend was seen for this band to be increased in the muscle of HRFI pigs $(P=0.055)$. There was also a trend for an interaction between line and health status $(P=$ $0.063)$, with the difference between the control and MhLI pigs being greater in HRFI than in the LRFI pigs; in the HRFI pigs, MhLI pigs had a significantly greater amount of the first, slower-migrating band $(P=0.018)$ relative to a reference sample than their controls. HRFI pigs also had a greater quantity of the second, fastermigrating band compared with their LRFI counterparts $(P<0.01)$. The second band was also analyzed as a ratio to the total immunoreactive protein per lane. This was performed to enable comparisons of the 2 bands irrespective of total Prdx-2 quantity. Infected pigs had a greater proportion of the second, fastermigrating band compared with control pigs $(P=$ 0.014). There was also a significant interaction between RFI line and infection status $(P=0.020)$, with the HRFI pigs showing a greater difference in band ratio between control and MhLI pigs than the LRFI pigs. Some common posttranslational modifications that have been documented to have an impact on Prdx-2 activity include phosphorylation (Przedborski, 2007), S-nitrosylation (Fang et al., 2007), and glutathionylation (Salzano et al., 2014). These modifications could lead to differences in migration patterns, similar to what was seen in the current study. These results demonstrate that potential differences in posttranslational modifications of $\operatorname{Prdx}-2$ exist between RFI lines and infection status. Pigs divergently selected for RFI appear to differ in Prdx-2 stress response owing to posttranslational modifications on the protein.

Hyperoxidized peroxiredoxin can indicate increased ROS concentration and oxidative stress (Poynton and Hampton, 2014). Hyperoxidized peroxiredoxin content in longissimus muscle samples was measured as an individual band. It was also measured relative to the detectable Prdx-2 in each sample (Figure 8), such that it could be measured as a proportion to the total Prdx-2. As an independent band, no significant differences for either line or health status were seen in hyperoxidized peroxiredoxin. However, a trend for an interaction between line and health status existed $(P=0.088)$, with hyperoxidized peroxiredoxin abundance greater in LRFI control pigs compared with

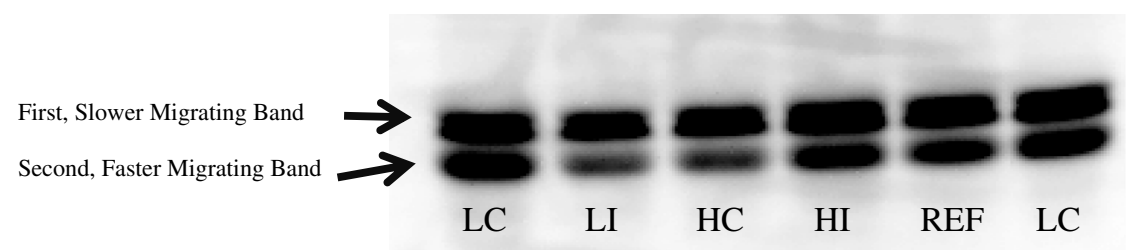

Figure 7. Representative western blot of the peroxiredoxin-2 resolved on a nonreducing gel. Samples were sarcoplasmic protein extracts from the longissimus muscle collected immediately following necropsy. The first and second bands were compared with the corresponding band in a sarcoplasmic protein extract from an unaged longissimus sample (REF). A comparison was also made between the bands within each sample by calculating the second band ratio to the total immunoreactive protein per lane. Samples are labeled based on their feed efficiency and infection status: Low RFI Control (LC), Low RFI Inoculated (LI), High RFI Control (HC), and High RFI Inoculated (HI). 


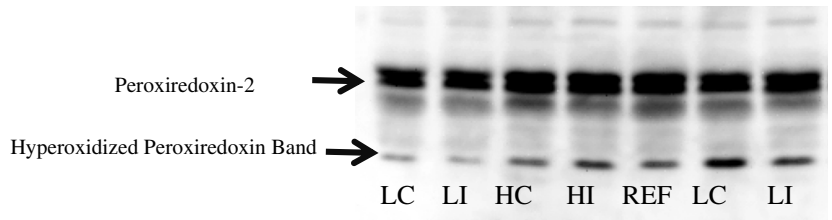

Figure 8. Representative western blot of hyperoxidized peroxiredoxin run on a nonreducing gel. Samples were sarcoplasmic protein extracts from the longissimus muscle collected immediately following necropsy. Hyperoxidized peroxiredoxin in samples was compared with the corresponding band in a sarcoplasmic protein extract from an unaged longissimus sample (REF). A comparison was also made between hyperoxidized peroxiredoxin and peroxiredoxin-2 within each sample by creating a ratio of the hyperoxidized peroxiredoxin band to the total immunoreactive protein per lane. Samples are labeled based on their feed efficiency and infection status: Low RFI Control (LC), Low RFI Inoculated (LI), High RFI Control (HC), and High RFI Inoculated (HI).

LRFI MhLI pigs and lower in HRFI control pigs compared with HRFI MhLI pigs (Table 3). The same trend for an interaction effect $(P=0.056)$ was also seen when hyperoxidized peroxiredoxin was compared to the total Prdx-2 per lane on nonreducing gels. Compared with Prdx-2, hyperoxidized peroxiredoxin was greater in LRFI compared with HRFI pigs $(P=0.028)$.

Although hyperoxidized peroxiredoxin content did not independently differ between RFI lines, skeletal muscle of the HRFI animals had a lower amount of hyperoxidized peroxiredoxin relative to total nonreduced Prdx-2, most likely because of a greater overall content of Prdx-2. The trending interaction that infection reduced hyperoxidized peroxiredoxin content in LRFI animals and increased hyperoxidized peroxiredoxin content in HRFI pigs further suggests a difference in oxidative stress response based on genetic selection for feed efficiency.

Although the RFI lines differed in Prdx-2 profile in longissimus skeletal muscle, infection status did not consistently affect Prdx-2 status. There are many explanations for this unanticipated lack of difference. Neither of the bacterial infections used in this study directly targets skeletal muscle tissue. L. intracellularis is small intestinal specific pathogen, whereas M. hyopneumoniae targets the respiratory tract and lungs. Thus, health-challenge-induced ROS production was limited in skeletal muscle (Helm et al., 2018a, 2018b). Greater ROS production and a corresponding alteration in the Prdx-2 profile may be more likely in tissues that are directly impacted by this health challenge, such as the small intestines and lungs for this experiment. Moreover, the subclinical nature of this challenge may have resulted in limited ROS production. Greater differences in the Prdx-2 profile are expected to exist in animals experiencing a health challenge.
It has become more clear that oxidative stress can affect metabolism through oxidation of proteins. Antioxidant proteins and their functions, therefore, play a dynamic role in muscle metabolism in response to stress. These results demonstrate that, in skeletal muscle, Prdx-2, GAPDH, and other antioxidant proteins may respond differently to oxidative stress challenge based on metabolic feed efficiency. This work illustrates the need to better understand the roles of antioxidant proteins such as Prdx-2 and GAPDH in livestock species so we may better understand how to manage them toward improving production efficiency.

\section{Acknowledgments}

This study was supported by a grant from the USDA Agriculture and Food Research Initiative (AFRI) National Institute for Food and Agriculture (NIFA) (Grant Numbers 2011-68004-30336, 201666015-2457, 2016-67017-247, and 2019-6701729181) and the Iowa Agricultural and Home Economics Experiment Station project number 3721. Author Patterson was supported by a fellowship from the Iowa Pork Producers' Association. Appreciation is expressed to Dr. Ed Steadham and Dr. Wes Schweer for their assistance with this project.

\section{Literature Cited}

Araki, K., H. Kusano, N. Sasaki, R. Tanaka, T. Hatta, K. Fukui, and T. Natsume. 2016. Redox sensitivities of global cellular cysteine residues under reductive and oxidative stress. J. Proteome Res. 15:2548-2559. https://doi.org/10.1021/acs. jproteome.6b00087.

Baty, J. W., M. B. Hampton, and C. C. Winterbourn. 2005. Proteomic detection of hydrogen peroxide-sensitive thiol proteins in Jurkat cells. Biochem. J. 389:785-795. https://doi.org/ 10.1042/BJ20050337.

Boddicker, N., N. K. Gabler, M. E. Spurlock, D. Nettleton, and J. C. M. Dekkers. 2011. Effects of ad libitum and restricted feed intake on growth performance and body composition of Yorkshire pigs selected for reduced residual feed intake. J. Anim. Sci. 89:40-51. https://doi.org/10.2527/jas.2010-3106.

Bottje, W., N. R. Pumford, C. Ojano-Dirain, M. Iqbal, and K. Lassiter. 2006. Feed efficiency and mitochondrial function. Poultry Sci. 85:8-14. https://doi.org/10.1093/ps/85.1.8.

Bottje, W., Z. X. Tang, M. Iqbal, D. Cawthon, R. Okimoto, T. Wing, and M. Cooper. 2002. Association of mitochondrial function with feed efficiency within a single genetic line of male broilers. Poultry Sci. 81:546-555. https://doi.org/10. 1093/ps/81.4.546.

Chang, X.-Z., D.-Q. Li, Y.-F. Hou, J. Wu, J.-S. Lu, G.-H. Di, W. Jin, Z.-L. Ou, Z.-Z. Shen, and Z.-M. Shao. 2007. 
Identification of the functional role of peroxiredoxin 6 in the progression of breast cancer. Breast Cancer Res. 9:R76. https://doi.org/10.1186/bcr1789.

Cruzen, S. M., S. C. Pearce, L. H. Baumgard, N. K. Gabler, E. HuffLonergan, and S. M. Lonergan. 2015. Proteomic changes to the sarcoplasmic fraction of predominantly red or white muscle following acute heat stress. J. Proteomics. 128:141153. https://doi.org/10.1016/j.jprot.2015.07.032.

Deblanc, C., F. Robert, T. Pinard, S. Gorin, S. Quéguiner, A. V. Gautier-Bouchardon, S. Ferré, J. M. Garraud, R. Cariolet, M. Brack, and G. Simon. 2013. Pre-infection of pigs with Mycoplasma hyopneumoniae induces oxidative stress that influences outcomes of a subsequent infection with a swine influenza virus of H1N1 subtype. Vet. Microbiol. 162:643651. https://doi.org/10.1016/j.vetmic.2012.11.028.

Dietz, K. J., S. Jacob, M. L. Oelze, M. Laxa, V. Tognetti, S. M. N. De Miranda, M. Baier, and I. Finkemeier. 2006. The function of peroxiredoxins in plant organelle redox metabolism. J. Exp. Bot. 57:1697-1709. https://doi.org/10.1093/jxb/erj160.

Dunkelberger, J. R., N. J. Boddicker, N. V. L. Serão, J. M. Young, R. R. R. Rowland, and J. C. M. Dekkers. 2015. Response of pigs divergently selected for residual feed intake to experimental infection with the PRRS virus. Livest. Sci. 177:132141. https://doi.org/10.1016/j.livsci.2015.04.014.

Fang, J., T. Nakamura, D.-H. Cho, Z. Gu, and S. A. Lipton. 2007. Snitrosylation of peroxiredoxin 2 promotes oxidative stressinduced neuronal cell death in Parkinson's disease. P. Natl. Acad. Sci. USA. 104:18742-18747. https://doi.org/10.1073/ pnas.0705904104.

Fazakerley, D. J., A. Y. Minard, J. R. Krycer, K. C. Thomas, J. Stöckli, D. J. Harney, J. G. Burchfield, G. J. Maghzal, S. T. Caldwell, R. C. Hartley, R. Stocker, M. P. Murphy, and D. E. James. 2018. Mitochondrial oxidative stress causes insulin resistance without disrupting oxidative phosphorylation. J. Biol. Chem. https://doi.org/10.1074/jbc.RA117.001254.

Flohe, L., and R. Harris. 2007. Peroxiredoxin Systems. Springer, New York, New York.

Genini, S., T. Paternoster, A. Costa, S. Botti, M. V. Luini, A. Caprera, and E. Giuffra. 2012. Identification of serum proteomic biomarkers for early porcine reproductive and respiratory syndrome (PRRS) infection. Proteome Sci. 10. https://doi.org/ 10.1186/1477-5956-10-48.

Ghaemmaghami, S., W.-K. Huh, K. Bower, R. W. Howson, A. Belle, N. Dephoure, E. K. O'shea, and J. S. Weissman. 2003. Global analysis of protein expression in yeast. Nature. 425:737-741. https://doi.org/10.1038/nature02046 Innature02046.

Grubbs, J. K., A. N. Fritchen, E. Huff-Lonergan, J. C. M. Dekkers, N. K. Gabler, and S. M. Lonergan. 2013a. Divergent genetic selection for residual feed intake impacts mitochondria reactive oxygen species production in pigs. J. Anim. Sci. 91:21332140. https://doi.org/10.2527/jas.2012-5894.

Grubbs, J. K., A. N. Fritchen, E. Huff-Lonergan, N. K. Gabler, and S. M. Lonergan. 2013b. Selection for residual feed intake alters the mitochondria protein profile in pigs. J. Proteomics. 80:334-345. https://doi.org/10.1016/j.jprot. 2013.01.017.

Hancock, J. T., D. Henson, M. Nyirenda, R. Desikan, J. Harrison, M. Lewis, J. Hughes, and S. J. Neill. 2005. Proteomic identification of glyceraldehyde 3-phosphate dehydrogenase as an inhibitory target of hydrogen peroxide in Arabidopsis. Plant Physiol. Bioch. 43:828-835. https://doi.org/10.1016/j. plaphy.2005.07.012.

Helm, E. T., A. C. Outhouse, K. J. Schwartz, J. C. M. Dekkers, S. M. Lonergan, W. M. Rauw, and N. K. Gabler. 2018a. Growth performance and tissue accretion of pigs presented with Mycoplasma hyopneumoniae and Lawsonia intracellularis dual challenge. J. Anim. Sci. 96:462-472. https://doi.org/ 10.1093/jas/skx074.

Helm, E. T., A. C. Outhouse, K. J. Schwartz, S. M. Lonergan, S. M. Curry, J. C. M. Dekkers, and N. K. Gabler. 2018b. Metabolic adaptation of pigs to a Mycoplasma hyopneumoniae and Lawsonia intracellularis dual challenge. J. Anim. Sci. 96:3196-3207. https://doi.org/10.1093/jas/sky220.

Hildebrandt, T., J. Knuesting, C. Berndt, B. Morgan, and R. Scheibe. 2015. Cytosolic thiol switches regulating basic cellular functions: GAPDH as an information hub? Biol. Chem. 396:523-537. https://doi.org/10.1515/hsz-2014-0295.

Karplus, P. A. 2015. A primer on peroxiredoxin biochemistry. Free Radical Bio. Med. 80:183-190. https://doi.org/10.1016/j. freeradbiomed.2014.10.009.

Kim, Y. H., E. Huff-Lonergan, J. G. Sebranek, and S. M. Lonergan. 2010. High-oxygen modified atmosphere packaging system induces lipid and myoglobin oxidation and protein polymerization. Meat Sci. 85:759-767. https://doi.org/10.1016/j. meatsci.2010.04.001.

Kim, J. H., S. J. Park, U. Chae, J. Seong, H. S. Lee, S. R. Lee, S. Lee, and D. S. Lee. 2018. Peroxiredoxin 2 mediates insulin sensitivity of skeletal muscles through regulation of protein tyrosine phosphatase oxidation. Int. J. Biochem. Cell B. https://doi.org/10.1016/j.biocel.2018.03.019.

Kornberg, M. D., P. Bhargava, P. M. Kim, V. Putluri, A. M. Snowman, N. Putluri, P. A. Calabresi, and S. H. Snyder. 2018. Dimethyl fumarate targets GAPDH and aerobic glycolysis to modulate immunity. Science. 360:449-453. https://doi.org/10.1126/science.aan4665.

Kuehne, A., H. Emmert, J. Soehle, M. Winnefeld, F. Fischer, H. Wenck, S. Gallinat, L. Terstegen, R. Lucius, J. Hildebrand, and N. Zamboni. 2015. Acute activation of oxidative pentose phosphate pathway as first-line response to oxidative stress in human skin cells. Mol. Cell. 59:359-371. https://doi.org/10. 1016/j.molcel.2015.06.017.

Leyens, G., I. Donnay, and B. Knoops. 2003. Cloning of bovine peroxiredoxins-gene expression in bovine tissues and amino acid sequence comparison with rat, mouse and primate peroxiredoxins. Comp. Biochem. Phys. B. 136:943-955. https:// doi.org/10.1016/S1096-4959(03)00290-2.

Lowry, O. H., N. J. Rosebrough, A. L. Farr, and R. J. Randall. 1951. Protein measurement with the folin phenol reagent. J. Biol. Chem. 193:265-275. https://doi.org/10.1016/S0021-9258 (19)52451-6.

Marco-Ramell, A., L. Arroyo, R. Peña, R. Pato, Y. Saco, L. Fraile, E. Bendixen, and A. Bassols. 2016. Biochemical and proteomic analyses of the physiological response induced by individual housing in gilts provide new potential stress markers. BMC Vet. Res. 12. https://doi.org/10.1186/ s12917-016-0887-1. 
Merlot, E., H. Gilbert, and N. Le Floc'h. 2016. Metabolic response to an inflammatory challenge in pigs divergently selected for residual feed intake. J. Anim. Sci. 94:563-573. https://doi.org/ 10.2527/jas2015-9445.

Outhouse, A., C., J. K. Grubbs, C. K. Tuggle, J. C. M. Dekkers, and N. K. Gabler. 2015. Changes in the protein profile of porcine liver in response to immune system stimulation. Iowa State University Animal Industry Report. 12. https://doi.org/10. 31274/ans_air-180814-1263.

Peralta, D., A. K. Bronowska, B. Morgan, É. Dóka, K. Van Laer, P. Nagy, F. Gräter, and T. P. Dick. 2015. A proton relay enhances $\mathrm{H} 2 \mathrm{O} 2$ sensitivity of GAPDH to facilitate metabolic adaptation. Nat. Chem. Biol. 11:156-163. https://doi.org/10.1038/ nchembio. 1720 .

Peskin, A. V., F. M. Low, L. N. Paton, G. J. Maghzal, M. B. Hampton, and C. C. Winterbourn. 2007. The high reactivity of peroxiredoxin 2 with $\mathrm{H} 2 \mathrm{O} 2$ is not reflected in its reaction with other oxidants and thiol reagents. J. Biol. Chem. 282:11885-11892. https://doi.org/10.1074/jbc.M700339200.

Poynton, R. A., and M. B. Hampton. 2014. Peroxiredoxins as biomarkers of oxidative stress. Biochim. Biophys. Acta. 1840:906-912. https://doi.org/10.1016/j.bbagen.2013.08.001.

Przedborski, S. 2007. Peroxiredoxin-2 links Cdk5 to neurodegeneration. Nat. Med. 13:907-909. https://doi.org/10.1038/ nm0807-907.

Reznick, A. Z., and L. Packer. 1994. Oxidative damage to proteins: Spectrophotometric method for carbonyl assay. Method Enzymol. 233:357-363. https://doi.org/10.1016/S0076-6879 (94)33041-7.

Richardson, E. C., and R. M. B. Herd. 2004. Biological basis for variation in residual feed intake in beef cattle. 2. Synthesis of results following divergent selection. Aust. J. Exp. Agr. 44:431-440. https://doi.org/10.1071/EA02221.
Salzano, S., P. Checconi, E.-M. Hanschmann, C. H. Lillig, L. D. Bowler, P. Chan, D. Vaudry, M. Mengozzi, L. Coppo, S. Sacre, K. R. Atkuri, B. Sahaf, L. A. Herzenberg, L. A. Herzenberg, L. Mullen, and P. Ghezzi. 2014. Linkage of inflammation and oxidative stress via release of glutathionylated peroxiredoxin-2, which acts as a danger signal. P. Natl. Acad. Sci. USA. 111:12157-12162. https://doi.org/10.1073/ pnas. 1401712111.

Schröder, E., J. A. Littlechild, A. A. Lebedev, N. Errington, A. A. Vagin, and M. N. Isupov. 2000. Crystal structure of decameric 2-Cys peroxiredoxin from human erythrocytes at $1.7 \AA$ resolution. Structure. 8:605-615. https://doi.org/10.1016/S09692126(00)00147-7.

Sies, H., C. Berndt, and D. P. Jones. 2017. Oxidative stress. Annu. Rev. Biochem. 86:715-748. https://doi.org/10.1146/annurevbiochem-061516-045037.

Stewart, I. I. 1999. Electrospray mass spectrometry: A tool for elemental speciation. Spectrochim. Acta B. 54:1649-1695. https://doi.org/10.1016/S0584-8547(99)00110-X.

Winger, A. M., N. L. Taylor, J. L. Heazlewood, D. A. Day, and A. H. Millar. 2007. Identification of intra- and intermolecular disulphide bonding in the plant mitochondrial proteome by diagonal gel electrophoresis. Proteomics. 7:4158-4170. https://doi.org/10.1002/pmic.200700209.

Winterbourn, C. C., and M. B. Hampton. 2008. Thiol chemistry and specificity in redox signaling. Free Radical Bio. Med. 45:549561. https://doi.org/10.1016/j.freeradbiomed.2008.05.004.

Wood, Z. A., E. Schröder, J. R. Harris, and L. B. Poole. 2003. Structure, mechanism and regulation of peroxiredoxins. Trends Biochem. Sci. 28:32-40. https://doi.org/10.1016/ S0968-0004(02)00003-8. 